\title{
Motivating CIO Advice Networking to Improve Firm Performance
}

\author{
Jeffrey J. Pittaway \\ Imperial College London \\ jeffrey.pittaway@imperial.ac.uk
}

\author{
Hamed Qahri-Saremi \\ DePaul University \\ hqahrisa@cdm.depaul.edu
}

\author{
Ali Reza Montazemi \\ McMaster University \\ montazem@mcmaster.ca
}

\begin{abstract}
Prior research has examined factors that motivate executives in general to seek advice from external peers. The literature is silent however regarding what IT governance mechanisms motivate CIOs to mindfully seek advice in their external advice networks. Our research shows that simply applying the advice of the prior literature in the CIO and IT governance context can be counterproductive. We analyze data from a survey of 99 municipal corporations to show that an effective configuration of IT governance mechanisms fits and changes over time with the firm's financial performance and state of IT enactment. The lessons learned are instructive for practitioners, while also highlighting the importance of attending to context in IT governance research.
\end{abstract}

\section{Introduction}

Firms bring about their own downfall when they become preoccupied with internal operations while less and less in touch with the external environment [6]. In so doing, they develop 'blindspots': perceptual filtering routines by which they attend to and select information that confirms their assumptions while ignoring information that disconfirms their assumptions. These filtering routines reinforce the existing mindset; they reduce ambiguity and provide a perception of orderliness that makes organizational life seem more predictable and, hence, more manageable. By producing a neatly ordered version of reality, they insulate firms from the complexities of the external environment. The key problem is these filtering routines lead to a lack of awareness regarding critical external happenings such as threats and opportunities in emerging technologies, changing customer demands, and intelligence failures [3]. The lack of awareness leads to misalignment between IT and the functioning of the organization in relation to the organization's environment [22], which can bring about organizational failure [6].

Notes: All authors are equal contributors; Research funded in part by Platform Value Now programme and Research Councils UK's Digital Economy Programme (EPSRC Grant No. EP/I038837/1)
Mitigating this risk requires a heightening of sensitivity to external events, such as threats and opportunities of emerging technologies. To this end, CEOs today are asking their CIOs to play bigger roles in the growth agenda by exploring for external advice regarding new strategic IT initiatives that can enable faster, more agile responses to emerging opportunities and threats, as part of IT governance [18]. External advice emanates from three sources: peer firms; market partners such as customers and suppliers; and, resources in the local market such as educated workforces [28]. Whereas the latter two sources are market-based, our focus is on new insight derived from peer firms in the same industry, which is the type of contextualized information that has great potential to improve firm performance [28].

By adopting a discerning or 'mindful' approach to seeking advice regarding strategic IT initiatives from peers, CIOs can learn from peers' successes and avoid their mistakes. They can reduce the risks of making a poor decision because estimates of the costs and potential returns can be made based on the experience of prior adopters [12]. They can also economize on costs of experimentation and broad market search for alternative solutions because these costs are borne by first-movers [40]. However, studies show that executives are not necessarily motivated to mindfully seek external advice from peers [20, 21]. Such lessmindful external advice seeking leads firms to adopt IT initiatives that harm or fail to improve firm performance [13]. It is in firms' interests, therefore, to employ IT governance mechanisms that can motivate CIOs to mindfully seek advice in their external advice networks.

The literature is silent, however, regarding IT governance mechanisms that motivate mindful search for strategic IT initiatives [27]. Thus, the open question remains: what IT governance mechanisms motivate CIOs to mindfully seek advice in their external advice networks? This is our research question.

To address the research question, we conducted a structured survey to test the explanatory power of two IT governance mechanisms in motivating CIOs to search for IT initiatives and IT-enabled change initiatives that could contribute to improve firm 
performance: (1) executive monitoring, and (2) financial incentives. Both mechanisms have been theorized to affect executives' motivations toward external advice seeking behaviors [21] but we do not know the combined effects in the context of CIOs' search for IT initiatives and IT-enabled change initiatives that could contribute to improve firm performance. Hence, we follow a prior study [21] of contextual factors to examine the effects of (3) prior firm financial performance on executives' adviceseeking behaviors. We also examine potential contingency of the foregoing effects upon (4) firms' state of path dependent learning to use IT strategically in daily routines (i.e., IT enactment [4]), which is thought to constrain what strategic IT initiatives firms are ready and motivated to learn [7]. Findings from our study elucidate how different IT governance configurations motivate mindful CIO advice seeking contingent upon focal-firm context. Implications for policymakers and promising avenues for future research close the paper.

\section{Theoretical foundation}

IT governance is an integral part of corporate governance, not only because officers' oversight of IT functions can be mandated by legislation [1], but also because active board/executive involvement in ITrelated decisions is associated with higher firm performance [14]. IT governance consists of two dimensions: (1) organizational leadership structures and (2) business processes that ensure that the firm's IT supports and extends its strategy and objectives [11]. The two dimensions are enabled by two underlying functions respectively that we adopt from the IS literature: (1) IT governance mechanisms [14] and (2) IT enactment [4].

Firms design and orchestrate IT governance mechanisms as a means of rationalizing, directing and coordinating the firm's IT-related decision making [14]. Well-designed and orchestrated IT governance mechanisms are expected to produce IT-related decisions and enactments that are more tightly aligned with a firm's strategic intentions. The IT governance team contributes to the value firms derive from IT by recognizing pain points, trigger events and other symptoms of need for organizational change; by goal setting and measurement, in which the impacts of IT on firm performance are vigilantly monitored; and by promoting change by rewarding managers' efforts in realizing value from enacting IT [7]. IT enactment refers to the notion that the features of technology are used by actors in their daily actions and routines, which contribute to outcomes such as firms' financial performance [4].
In the context of IT enactment, it is the CIO that is responsible for identifying strategic objectives to change some aspect of their firm, seek available technologies or strategies which may fit their objectives, and then provide the 'go ahead' for actors within the firm to acquire and implement the IT in support of achieving the strategic objectives [17]. It is also the CIO that possesses both the general lexicon of business management and the specialized language and knowledge of IS practitioners that facilitates discourse on strategic IT initiatives with colleagues at peer firms [36]. Hence, it is the CIO that is expected to be the foremost boundary spanner that facilitates inflows of fresh information with new insights from peer firms that can help to improve IT enactment.

A boundary spanner can be defined as an individual employed at a firm who currently has, or previously had, direct contact(s) with peers at other firms' through professional associations, meetings, conferences, task forces, and so forth [45]. Through these personal encounters, boundary spanners form relationships with contacts in other firms that provide the conduit for inflows of advice from peer firms [28]. CIOs' boundary spanning role is found to significantly affect strategic IT initiative performance by importing external knowledge and integrating internal knowledge [25]. As boundary spanners, CIOs are influenced by peers' choices of IT products or services, and they benchmark the firm's business benefits derived from IT usage against those derived by other firms. The external 'advice network' is constituted when the CIO decides which peer firms to turn to for advice [29].

Access to peers in CIO's external advice networks, and the perspectives they formed through the experience of implementing an IT and strategic IT initiative in their own context, can help CIOs to make sound judgments about the likely costs and payoffs in their own organization, when committing to the strategic IT initiative is best to take place, and how implementation can best be pursued [37]. Hence, on-going exploration in CIOs' advice networks can help firms to remain viable over time by continually renewing the ability to adapt; that is, to maintain alignment between IT and the functioning of the organization in relation to the environment. This ability to adapt is a key factor in firms' financial performance over time.

The motivation to improve firm performance is central to the thesis of mimetic isomorphism, which states that firms within an industry come to imitate each other in the structures (e.g., technologies) and strategies they implement because they learn from each other about particular technologies and strategies adopted by admired (i.e., higher performing) firms and mimic those firms' IT and strategy choices [23]. In so doing, CIOs can improve their own firm's financial performance, 
because higher performing firms have knowledge of more rewarding opportunities on which the seeker can capitalize. Therefore, it is in the best interests of the firm to motivate CIOs to on-going advice seeking for more rewarding strategic IT initiatives.

Management theorists contend that executives have a natural motivation toward an instrumentality of selfinterest [20]. In this view, executives are motivated to seek advice from peers in similar contexts, reasoning that their advice is likely to affirm and help defend the executives' current strategic decisions, whereas peers in different contexts are more likely to offer alternative and disconfirming advice. This reasoning would suggest that CIOs are motivated to seek advice from peers at firms with similar performance, rather than peers at admired, higher performing firms. The problem with this advice-seeking behavior is that the CIO foregoes the payoffs of learning how to replicate more successful strategic IT decisions from higher performing firms, how to avoid pitfalls in the course of implementing a more rewarding strategic IT initiative, and how to make sound judgments about the likely costs and payoffs and when committing to the strategic IT initiative is best to take place [12]. In short, advice seeking motivated by an instrumentality of self-interest can expose the firm to agency costs in the form of poor strategic IT decisions. This self-interested motivation consequently results in advice-seeking behavior that can be labelled 'lessmindful' toward the best interests of the firm [41].

Notwithstanding the interests of the firm in motivating CIOs to mindful advice seeking, the literature is silent with regards to IT governance mechanisms at firms' disposal that can motivate CIOs to seek external advice for strategic IT initiatives that are more rewarding for the firm. To ameliorate this gap, we proceed to theorize and empirically assess the causal relationships between IT governance mechanisms and CIO's external advice seeking behaviors. The proposed theoretical framework, depicted in Figure 1, is explained next.

\section{Hypotheses development}

In the perspective of executive advice network generation literature, an executive commences advice seeking when encountering a problem or opportunity the individual does not have sufficient confidence or knowledge to solve alone (e.g., [29]). Particularly when the problem or opportunity involves unstructured, vague, and complex situations or an uncertain environment, executives are motivated to seek external peers to help interpret the problem, decompose it, identify the relevant and significant problem parameters, and possible solutions. And after finding a possible solution, executives may contact a peer to affirm ideas, confirm judgments, or validate beliefs. This perspective does not exhaust all possible sources of executives' motivations for seeking advice in external advice networks. However, we believe it identifies firm performance as perhaps the most salient contextual source of motivations for CIOs seeking to gain alignment between information technology (IT) and the functioning of the organization to survive in an uncertain environment. We will therefore examine firm performance as a contextual motivating factor for CIOs. But first, we develop hypotheses regarding what IT governance mechanisms motivate CIOs to mindfully seek advice in their external advice networks.

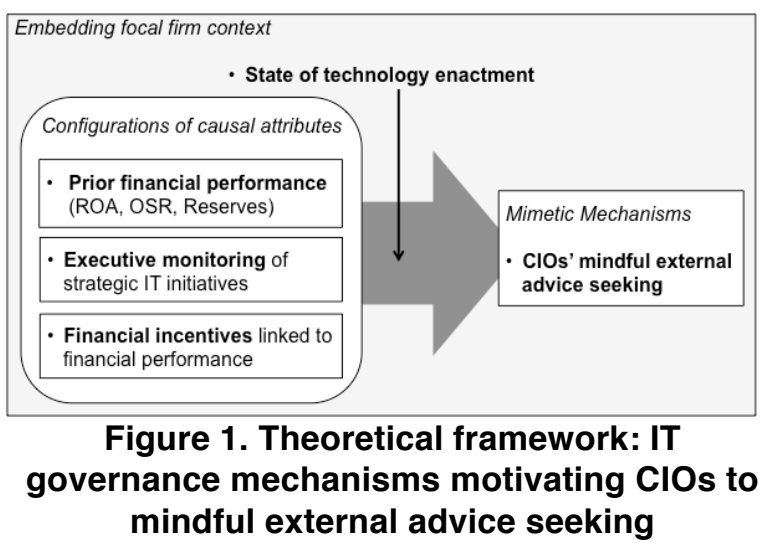

\subsection{Mindful external advice seeking (outcome)}

Following Fiol and O'Connor [9] we conceptualize managers' mindfulness in terms of perceptual accuracy, which can be defined as how accurately managers perceive the value of external strategic IT initiatives. In our case, perceptual accuracy would refer to the congruence between the value CIOs subjectively perceive of adopting external advice regarding strategic IT initiatives, and the objective value of such initiatives in the referent firms. The objective value of strategic IT initiatives should be assessed in terms of the relative financial performance of the referent firm [38], but executives are not necessarily motivated to critically evaluate advice by seeking such objective evidence. Instead, executives can have a self-interested motivation to seek advice from poor performers in an effort to defend their prior strategic decisions, which creates agency costs for the firm when IT initiatives fail to contribute to improved financial performance [21]. Therefore, it is in the best interests of the firm to motivate CIOs to actively search for advice from referents at firms that objectively contributes to higher financial performance (i.e., mindful).

Next, we theorize the antecedents and contextual factors that can motivate CIOs to mindful advice seeking in the interests of the firm. We address the 
antecedents in terms of (1) executive monitoring, and (2) financial incentives, and we address contextual factors in terms of (3) prior firm financial performance and (4) focal firm state of IT enactment as follows.

\subsection{IT Governance}

In order to motivate CIOs to seek out more rewarding IT opportunities in the best interests of the firm, rather than taking a self-interested defensive approach to advice seeking, corporate governance researchers advocate for governance mechanisms that increase the alignment of executives' personal interests with the interests of the firm, key among which is strong firm financial performance [21]. Such alignment essentially increases the personal consequences to CIOs of meeting, or failing to meet, firm financial performance targets. Two general mechanisms for aligning CIOs' interests with the firms' interest in strong financial performance are (1) executive monitoring of CIOs' strategic decisions, and (2) financial incentives that are contingent upon achieving their firms' financial performance objectives as follows [21].

3.2.1. Executive monitoring. One of the most common corporate governance mechanisms for monitoring and oversight of IT is the IT steering committee [14]. The IT steering committee consists of senior executives from multiple areas of the firm that, collectively, have oversight to ensure that strategic IT initiatives are attuned to the firm's risk tolerance and strategic directions [44]. Executives that vigilantly monitor strategic decision-makers do not simply defer to them or act as "rubber stamps" for their decisions [21]. Instead, they demand justifications and explanations for proposed strategic initiatives and constructively criticize proposed initiatives when they believe those initiatives are ill advised. This would suggest that executive monitoring motivates CIOs to validate that new advice contributes to relatively higher performance in the source firm (i.e., mindful) instead of favoring advice from lower performing firms to defend CIOs' prior strategic decisions (i.e., less-mindful). Based on the literature we can advance the hypothesis:

Hypothesis H1. Executive monitoring motivates CIOs to mindfully seek external advice from peer firms.

3.2.2. Financial incentives. To the extent that executives benefit financially from improvements in their firm's financial performance, they are more willing to engage in behaviors that enhance the firm's financial performance [21]. To that end they are motivated to make superior strategic decisions, and consequently they are motivated to seek out a wide range of opinion on strategic issues from peer firms. Because higher performing firms know about more rewarding opportunities [23], we would expect CIOs motivated by an instrumentality of improved firm performance to seek advice from higher performing firms (i.e., mindful) instead of favoring advice from lower performing firms to defend CIOs' prior strategic decisions (i.e., lessmindful). Based on the literature, we can advance the hypothesis:

Hypothesis H2. Financial incentives to improve firm performance motivate CIOs to mindfully seek external advice from peer firms.

The foregoing section discussed IT governance mechanisms to motivate mindful advice-seeking behaviors. Next, we discuss contextual factors.

\subsection{Focal firm prior financial performance}

Extant literature states that poor firm financial performance relative to peers is an important source of uncertainty that is likely to impel decision makers to search for information regarding more rewarding opportunities [20]. Low firm financial performance signals gaps between strategic IT decisions and the firm's performance requirements, which calls into question the veracity of the current strategy. To the extent that CIOs' beliefs about strategy are reflected in the firm's current strategy, they feel uncertainty regarding their beliefs that informed their strategic decisions. This uncertainty evokes psychological distress and anxiety, which activates a deep-seated motive to restore a sense of certainty. To restore a sense of certainty, executives tend to seek external advice from executives at other firms in an effort to confirm or update their underlying interpretations of the environment. When actors regain a sense of certainty, they tend to stop searching for advice [5]. This would suggest that poor firm performance motivates CIOs to seek advice from higher performing firms (i.e., mindful) instead of favoring advice from lower performing firms to defend CIOs' prior strategic decisions (i.e., lessmindful). Based on the literature, we can advance the hypothesis:

Hypothesis H3. Poor firm financial performance motivates CIOs to mindfully seek advice from peer firms.

\subsection{Focal firm state of IT enactment}

Organizational change proceeds by combining the insights of new information with existing knowledge of how to operate, thereby learning to tap the unexplored potential of current IT and/or finding ways to exploit new IT in practice [28]. The potential for firms to understand and act on new information (e.g., new ideas of how to enact IT in support of better and more efficient 
organizational performance) is constrained by firms' absorptive capacities. The premise of absorptive capacity states that the potential for a firm to understand fresh insights (e.g., regarding the potential of IT) and exploit it in practice in a future period $(t+1)$ is a function of the accumulated knowledge they can exploit in the current period $(t)$. Exploitation is a dynamic capability based on routines that allow the firm to refine, extend, and leverage existing competencies or to create new ones by incorporating new knowledge into its operations; that is, firms' realized absorptive capacities. In turn, intensity of effort to exploit knowledge in the current period is critical to enhancing firms' potential to understand and act on new knowledge in a future period.

This cumulative path dependent learning process is reflected in the literature as characteristically distinct states of IT enactment (e.g., [7, 16]), where more advanced states are thought to contribute to better and more efficient organizational performance [4]. IT enactment can be assessed in terms of five states as follows [7, 15]. In state 1, Initial, firms know how to enact IT in support of business processes that are ad hoc and monitored in local departments. They are ready to learn how to standardize IT infrastructure. In state 2, Repeatable, firms know how to enact a standardized IT infrastructure, but business processes remain ad hoc and locally monitored. The firm is ready to learn how to enact the infrastructure to efficiently coordinate business processes across functional departments. In state 3, Defined, firms know how to exploit IT infrastructure for sharing data to support and monitor cooperation between departments, and they are ready to learn how to standardize business processes within and across departments. In state 4, Managed, firms know how to exploit enterprise systems to support and monitor standardized end-to-end enterprise processes, and they are ready to learn how to extend their enterprise systems to exploit new external technologies. In state 5, Optimized, firms know how to rapidly connect and disconnect new technologies in their supply chains and industry to their enterprise systems without damaging the integrity of core data and business processes.

The salient insight of the foregoing 'states' view of organizational context is that firms in different states of technology enactment are likely to have different capacities to understand, enact and monitor the performance impacts of strategic IT initiatives emanating from CIOs' external advice networks. Therefore, we can expect that the combined effects of our antecedents - executive monitoring, performancebased financial incentives, prior firm financial performance - on CIO's motivations towards mindful advice seeking will be contingent upon firms' state of IT enactment. Based on the literature, we can advance our final hypothesis:
Hypothesis H4. The configurations of IT governance mechanisms that influence CIOs to mindfully seek external advice are contingent upon the organization's state of IT enactment.

\section{Methodology}

We assessed the four stated hypotheses in the context of local governments in Canada. These organizations are corporations responsible for the administration of twelve public services: public administration, fire and police services, roadways, public transit, drinking water, wastewater, storm water management, solid waste management, parks and recreation, library services, and land use planning. The corporations' executives have been under tremendous pressure to reform traditional business models for public service delivery because they need to develop innovative ways to address fiscal restraints while fulfilling citizen demands for public service [30]. In addition, IT governance is a legally mandated element of corporate governance in Canada [1]. Thus, local governments in Canada provide a potentially rich context in which to study mechanisms of IT governance. Furthermore, local governments in Canada have a common industry association, the Municipal Information Systems Association (MISA), which has the explicit mandate to provide "a forum for the interchange of information between municipal representatives, leading to the more efficient use of municipal information systems" (misa.on.ca). Thus, local governments in Canada provide a potentially rich context in which to study CIOs' external advice networking behaviors with peers.

Data were collected from CIOs by means of a structured questionnaire, which consisted of preexisting measures from the literature implemented in the form of a web-based survey. We obtained a database of potential survey respondents from LexisNexis. The original database had 505 English-speaking local governments across Canada that fit the MISA member profile (i.e., minimum $\$ 5.2$ million in annual revenues). Using the MISA member profile assured us that the corporations recruited had sufficient scope for strategic IT initiatives that could potentially benefit from "the interchange of information between municipal representatives" (misa.on.ca), while excluding very small corporations whose size could bias the analysis [39].

Recruitment letters were mailed to the CIOs. This resulted in 106 CIOs responding as potential advice seekers. Data for seven respondents were incomplete and therefore dropped from further analysis, and data for 99 respondents remained. The response rate of $19.6 \%$ was within the accepted range of prior unsolicited IS 
surveys that involved $\mathrm{CIO}$ respondents ( $12 \%$ to $24.6 \%$, $[2,31,39,42])$.

We applied fuzzy set qualitative comparative analysis (fsQCA; http://www.fsqca.com) to assess configurations of causal attributes in qualitative data that explain the sample of cases [10, 34]. fsQCA identifies configurations in which individual causal attributes are consistently present when the desired outcome is present, or consistently absent when the desired outcome is present, or not associated consistently with the desired outcome. fsQCA also estimates the coverage of each configuration, which refers to the proportion of cases where the outcome can be explained by the respective configuration of causal attributes. However, it is also desirable to identify configurations that appear systematically and not by chance. We therefore confirmed that our sample sizes for fsQCA meets or exceeds the 15 cases suggested by Marx [19]. This threshold is recommended because it can identify systematic configurations and reject random configurations for our model with five causal attributes.

Results from evaluating descriptive statistics of our sample versus the population using ANOVA show that the distribution of local governments in each province/territory by frequency $(t=0.043)$ and percentage $(t=1.000)$ did not differ significantly from the population. These results validate the representativeness of the sample with respect to the population of local governments in the original database. The frequency distribution of local governments by state of IT enactment showed that too few local governments were at state 5 or state 1 to include in our analyses. Therefore, our analyses focused on the $96 \%$ of firms in states 2,3 or 4 of IT enactment. We then combined respondent data with archive data from audited annual financial reports for seekers and their named sources. The combined dataset represented 114 unique matched pair source-seeker dyads for analysis.

\subsection{Measurement operationalization}

4.1.1. Advice seeking dyads. We adopted the Cross and Sproull [5] instrument to ask respondents to name the CIOs/IT directors at up to five peer local governments whom they believed were most helpful in providing advice (regarding strategic IT initiatives) in the past twelve months. Obtaining the names of advice sources allowed us to identify matched pair source-seeker dyads.

4.1.2. Mindful external advice seeking (outcome). Following the perceptual accuracy conceptualization of mindful advice-seeking, we next computed the relative fit between the perceived helpfulness [5] of source firm's advice as reported by CIOs, and the source firm's actual financial performance relative to the seeker firm's actual financial performance (i.e., the subjective versus objective value [38]). For objective measures, we adopted three financial ratios that are used in public reporting: return on assets (ROA), own source revenues (OSR), and financial reserves (RESV). Perceptual accuracy was computed as the fit between the perceived value and objective value of source's advice in each dyad to obtain an index of mindful advice seeking ranging from ' 0.00 -poorest fit (lowest perceptual accuracy)' to '1.00-best fit (highest perceptual accuracy)'.

4.1.3. Prior firm financial performance. The three financial ratios (ROA, OSR, RESV) computed for each seeker firm were used to assess the effects of seeker firms' prior financial performance on external advice seeking behavior, and were compared with the sample mean (i.e., higher or lower, H3).

4.1.4. Executive monitoring. We adopted the preexisting and validated 3 -item instrument for measuring board/executive monitoring from Westphal [43], in order to measure the extent of executive monitoring by the IT steering committee.

4.1.5. Financial incentives. We adopted the preexisting validated instrument from a prior study [24] that asks respondents to indicate the extent to which the firm uses performance-based compensation and the extent to which performance-based compensation systems are closely linked to improved firm financial performance. This instrument is designed to assess managers' motivations to seek advice based on the perceived significance of the financial reward and the link to financial performance outcomes.

4.1.6. Focal firm state of IT enactment. In order to assess firms' states of IT enactment, we adopted an instrument for the government context from Jaklič and Štemberger [15] that was based on the industry standard COBIT framework $[7,26]$ and asks CIOs which state description best characterizes their organization at present: Initial, Repeatable, Defined, Managed, Optimized, as defined in section 3.4. CIOs' responses were coded as nominal variables (1-5) to group firms in similar states for analysis.

\subsection{Reliability and validity of questionnaires}

Five experts reviewed the initial structured questionnaire. Based on their feedback, we made minor changes to the questionnaire to fit the Canadian local 
government context (e.g., the CIO is typically called an 'IT director'). We assessed the corrected inter-item correlations and Cronbach's alpha of the multi-item executive monitoring measure to mitigate artifacts in our results due to measurement error. The three-item measure exhibited good convergent validity and reliability $(\alpha>0.7)$ [8].

\subsection{Analysis}

We computed causal configurations based on 9 truth tables: 3 different outcome measures (i.e., mindful advice seeking based on ROA, OSR and RESV ratios) $\mathrm{x} 3$ sets of firms at states 2, 3 or 4 of IT enactment. Three of the nine truth tables were dropped from further analysis because insufficient cases met the minimum consistency criterion of $0.80[10,32]$. This left six truth tables for further analysis: two truth tables for firms in each of the three analyzed states of IT enactment. Based on these data, we proceeded to compute the causal configurations that explain CIOs' mindful advice seeking.

We produced two relevant reports for each analysis using fsQCA 2.5 [33] in accordance with Ragin and Giesel [34]: (1) the core solution, which shows core causal attributes that are present in all cases exhibiting the outcome (mindful advice seeking), and (2) the parsimonious solution, which weighs counterfactual cases against supporting cases for each combination and then identifies peripheral causal attributes that can have an important combined effect on the outcome. In accordance with the reporting protocol of prior literature (e.g., [10]), the core and peripheral causal attributes that emerged from fsQCA are depicted with large and small circles respectively in Table 1 . A shaded circle (O) denotes a causal attribute that, when present, has a causal effect on the outcome, mindful advice seeking. A circle crossed out $(\otimes)$ denotes a causal attribute that when absent has a causal effect on the outcome. Hence, the six columns in Table 1 labelled C1, C2 ... C6 depict six alternative configurations of causal attributes that in combination (i.e., logical AND relationships) with each other explain the outcome, CIOs' mindful advice seeking, for firms at a given state of IT enactment.

Redundant configurations of core and peripheral causal attributes have been combined for presentation in Table 1 in the interest of parsimony [34]. Consequently, the coverage for each configuration (i.e., the explanatory power of a causal configuration) reported in Table 1 is the minimum coverage based on core causal attributes only. Coverage estimates the proportion of cases where the outcome can be explained by the respective configuration of causal attributes. All causal configurations reported in Table 1 exceed the minimum configuration consistency threshold of 0.75 , which indicates good explanatory power in configurational analysis [32].

Table 1. Results of configurational analyses

\begin{tabular}{|c|c|c|c|c|c|c|}
\hline Firms in: & \multicolumn{2}{|c|}{ State 2} & \multicolumn{2}{|c|}{ State 3} & \multicolumn{2}{|c|}{ State 4} \\
\hline $\begin{array}{l}\text { Causal Configurations: } \\
\text { Causal Attributes }\end{array}$ & $\begin{array}{c}\text { C1 } \\
\text { OSR }\end{array}$ & $\begin{array}{c}\mathrm{C} 2 \\
\text { RESV }\end{array}$ & $\begin{array}{c}\mathrm{C} 3 \\
\mathrm{ROA}\end{array}$ & $\begin{array}{c}\text { C4 } \\
\text { RESV }\end{array}$ & $\begin{array}{c}\text { C5 } \\
\text { ROA }\end{array}$ & $\begin{array}{c}\text { C6 } \\
\text { OSR }\end{array}$ \\
\hline \begin{tabular}{|ll}
$\begin{array}{l}\text { Prior } \\
\text { Financial }\end{array}$ & (ROA)
\end{tabular} & & & $\otimes$ & $\otimes$ & & \\
\hline Performance $_{\text {(OSR) }}$ & & & $\otimes$ & $\otimes$ & & ) \\
\hline (Reserves) & & & & $\otimes$ & & $\otimes$ \\
\hline $\begin{array}{l}\text { Executive } \\
\text { Monitoring } \\
\text { Financial } \\
\text { Incentives }\end{array}$ & - & - & $\otimes$ & $\otimes$ & & \\
\hline $\begin{array}{r}\text { Coverage: } \\
\text { Consistency: }\end{array}$ & $\begin{array}{l}0.53 \\
>0.75 \\
\end{array}$ & $\begin{array}{r}0.59 \\
>0.75 \\
\end{array}$ & $\begin{array}{r}0.29 \\
>0.75 \\
\end{array}$ & $\begin{array}{c}0.44 \\
>0.75 \\
\end{array}$ & $\begin{array}{r}0.29 \\
>0.75 \\
\end{array}$ & $\begin{array}{l}0.82 \\
>0.75 \\
\end{array}$ \\
\hline
\end{tabular}

\section{Results}

Results from configurational analysis (Table 1) address the research question: what IT governance mechanisms motivate CIOs to mindfully seek advice in their external advice networks? The results show that CIOs of firms in state 2 of IT enactment are motivated to mindful advice seeking when their firms have high efficiency (ROA), independence from grants from higher-tier governments (OSR), and cash reserves, (RESV) and the effect is enhanced by executive monitoring of IT impacts (column C1). The latter two conditions, cash reserves and executive monitoring, are sufficient to motivate advice seeking from peers with high cash reserves (column $\mathrm{C} 2$ ).

CIOs of firms in state 3 of IT enactment are motivated to mindful advice seeking when their firm has low operating efficiencies (ROA) and high dependency on grants from higher tiers of government (OSR), and when executives actively monitor IT impacts on firm performance (column C3), as predicted. However, the absence of financial incentives linked to efficiency motivates mindful advice seeking in state 3 firms, contrary to our prediction (Hypothesis H2, which we discuss below).

For CIOs of firms in state 4 of IT enactment, financial incentives linked to efficiency provide a strong explanation for CIOs' mindful advice seeking, as predicted (column C5). Whereas these results can provide guidance for practitioners and policy makers, the findings for warrant further discussion of our hypotheses as follows.

\section{Discussion and Implications}

Whereas prior research has examined factors that motivate executives in general to seek advice from peers, the literature is silent regarding IT governance 
mechanisms that motivate mindful search for strategic IT initiatives. Our findings show that simply applying the advice of the prior literature in the CIO and IT governance context can be ineffective or counterproductive under certain conditions. In the discussion that follows, we tease out this context sensitivity to identify what IT governance mechanisms motivate CIOs to mindfully seek advice in their external advice networks in specific contexts.

\subsection{State-appropriate IT governance}

As per Hypothesis H1, prior literature advocates executive monitoring to motivate executives' mindful external advice seeking [21]. We found support for this hypothesis in the $\mathrm{CIO}$ and IT governance context in five but not all six configurations. Configuration C5 shows that for firms in State 4 IT enactment, the significance of executive monitoring pales in comparison to financial incentives in motivating CIOs to seek advice from higher efficiency (ROA) peer firms. The results suggest that firms should adopt executive monitoring as a significant IT governance mechanism for motivating CIOs mindful to search mindfully for efficiencyimproving initiatives in States 2 and 3, but the IT governance configuration should be changed to emphasize financial incentives in State 4.

As per Hypothesis H2, prior literature advocates financial incentives to motivate executives' mindful external advice seeking [21]. In the CIO and IT governance context, however, we found financial incentives were not causal attributes, or should be absent, or were consistent causal attributes, depending on a firm's state of IT enactment as follows.

In the context of firms in state 2 of IT enactment, financial incentives were not consistent causal attributes explaining CIOs' motivations for mindful advice seeking. Instead, the sufficient causal attribute was poor financial performance (which we discuss later).

In state 3 of IT enactment, the absence of financial incentives explains CIOs' motivations for mindful advice seeking, contrary to the predicted effect. This may be explained by research [35] that suggests firms in state 3 face the challenge of investing in new integrated enterprise systems such as ERP. The implementation of ERP incurs high costs that include but are not limited to software licenses, maintenance, project management, change management, and user training, and the financial payoffs can be delayed for years. In this case, tying CIOs' financial incentives to short-term improvements in financial results will have the opposite of the intended effect: it will ensure that CIOs' personal interests are misaligned and directly conflict with the best interests of the firm to make the necessary investments in ERP.
In state 4 of IT enactment, the presence of financial incentives explains CIOs' motivations for mindful advice seeking (as predicted). This may be explained by research [35] that suggests firms in state 4 have rationalized and replaced with ERP a large number of disparate, incompatible, but often interlinked legacy systems that impose high costs for updates, support, maintenance and license fees for redundant functionality. Hence, it is not until state 4 that firms begin to reap the efficiency benefits of their investments in ERP. For this reason, aligning CIO interests with improved operating efficiencies can be an effective IT governance mechanism for firms in state 4 of IT enactment.

For practitioners, our findings regarding the sensitivity of IT governance mechanisms to state of IT enactment (Hypothesis H4) underscore the need for executives and policymakers to actively align incentive plans with the changing state of the firm and to avoid relying on a single approach if the firm is to motivate CIOs to actively pursue advice in the best interests of the firm. For researchers, confirmation of a moderating effect in Hypothesis H4 highlights the importance of attending to differences in context when analyzing IT governance data from firms in different states of IT enactment.

\subsection{The interaction of performance and state of IT enactment}

As previously stated, executive advice network generation literature contends that an executive commences advice seeking when encountering a problem or opportunity the individual does not have sufficient confidence or knowledge to solve alone. Prior literature adopting this view proposed poor financial performance as a poignant example. McDonald et al. ([21]) specifically examined whether executives facing poor performance would seek out friendship peers to confirm their views (i.e., less-mindful), or seek out other peers to disconfirm false assumptions (i.e., mindful). They found both responses which, they explained, could mean that some executives become defensive and seek validation of their current strategy when they perceive a threatening problem, while other executives seek out more advice with discretion to inform alternative strategies. In the $\mathrm{CIO}$ and IT governance context, however, our findings support another explanation - the interaction of performance and state of IT enactment as a contextual factor - as follows.

Findings for Hypothesis H3 concerning prior firm performance exhibited opposing causal effects in firms at different states of IT enactment. Specifically, poor prior firm financial performance can motivate mindful advice seeking (as predicted) in the context of firms in 
state 3 and 4 of IT enactment. However, CIOs embedded in firms in state 2 of IT enactment that engage in mindful advice seeking typically have above average prior financial performance, contrary to the prediction of Hypothesis H3. The latter effect is consistent, however, with conjecture in the extant literature when we consider the focal firm context. Firms in state 2 lag behind their state 3 and 4 peers in implementing ERP. On one hand, CIOs of firms in state 2 could feel justified in not adopting ERP more quickly and comprehensively when firm financial performance is above average. On the other hand, firms "performing relatively poorly may be preoccupied with their competitive disadvantage. A firm in this category, concluding that it has fallen behind others in innovating with IT, may come to disparage its own competence in this arena. Consequently, in contemplating the innovative activities of others, it may be more inclined to look for models to slavishly emulate than to critically appropriate for local fit" ([37], p. 573).

For practitioners, this finding suggests that low performing firms in state 2 of IT enactment can be especially difficult to engage in industry discourse, and consequently industry associations and/or (higher tier) governments need to adopt different approaches to reach and educate these firms. For researchers, this conclusion suggests that more research is needed to understand how to engage low performing state 2 firms in learning how to use IT to improve firm performance from higher performing peer firms in their industry.

In sum, our findings elucidate the significance of IT governance in motivating mindful search for more rewarding IT initiatives. However, no single IT governance approach is most effective in promoting mindful external advice seeking in all cases. For practitioners, the findings underscore the need to strategically update the configuration of IT governance mechanisms as the firm matures to different states of IT enactment. For researchers, the findings underscore the need to attend to focal firm context when examining the motivating effects of IT governance configurations. The proposed theoretical framework incorporates sensitivity to differences in firms' context and advances a foundation for future research on IT governance concerning mimesis and diffusion of IT.

\section{References}

[1] Bart, C., and O. Turel, "IT and the board of directors: An empirical investigation into the "governance questions" Canadian board members ask about IT", Journal of Information Systems, vol. 24(2), 2010, pp. 147-172.

[2] Chen, D.Q., D.S. Preston, and W. Xia, "Antecedents and effects of CIO supply-side and demand-side leadership: A staged maturity model", Journal of Management Information Systems, vol. 27(1), 2010, pp. 231-272.
[3] Choi, J., and H. Wang, "Stakeholder relations and the persistence of corporate financial performance", Strategic Management Journal, vol. 30(8), 2009, pp. 895-907.

[4] Cordella, A., and F. Iannacci, "Information systems in the public sector: the e-government enactment framework", Journal of Strategic Information Systems, vol. 19(1), 2010, pp. 52-66.

[5] Cross, R., and L. Sproull, "More than an answer: Information relationships for actionable knowledge", Organization Science, vol. 15(4), 2004, pp. 446-462.

[6] Cunha, M.P.e., and R. Chia, "Using teams to avoid peripheral blindness", Long Range Planning, vol. 40(6), 2007, pp. 559-573.

[7] Debreceny, R.S., and G.L. Gray, "IT governance and process maturity: A multinational field study", Journal of Information Systems, vol. 27(1), 2013, pp. 157-188.

[8] Eisenhardt, K., and B.N. Tabrizi, "Accelerating adaptive processes: product innovation in the global computer industry", Administrative Science Quarterly, vol. 40(1), 1995, pp. 84-110.

[9] Fiol, C.M., and E.J. O'Connor, "Waking up! Mindfulness in the face of bandwagons", Academy of Management Review, vol. 28(1), 2003, pp. 54-70.

[10] Fiss, P.C., "Building better causal theories: A fuzzy set approach to typologies in organization research", Academy of Management Journal, vol. 54(2), 2011, pp. 393-420.

[11] Gottschalk, P., CIO and corporate strategic management: Changing role of $\mathrm{CIO}$ to $\mathrm{CEO}$, IGI Global, 2007.

[12] Greve, H.R., "Managerial cognition and the mimetic adoption of market positions: What you see is what you do", Strategic Management Journal, vol. 19(10), 1998, pp. 967988.

[13] Greve, H.R., "Fast and expensive: the diffusion of a disappointing innovation", Strategic Management Journal, vol. 32(9), 2011, pp. 949-968.

[14] Huang, R., R.W. Zmud, and R.L. Price, "Influencing the effectiveness of IT governance practices through steering committees and communication policies", European Journal of Information Systems, vol. 19(3), 2010, pp. 288-302.

[15] Jaklič, J., and M.I. Štemberger, "Towards t-government by increasing process maturity in public sector", in Weerakkody, V., Janssen, M., and Dwivedi, Y.K. (Eds.), Handbook of Research on ICT-Enabled Transformational Government: A Global Perspective, 2009, pp. 15-34.

[16] Layne, K., and J. Lee, "Developing fully functional egovernment: A four stage model", Government Information Quarterly, vol. 18(2), 2001, pp. 122-136.

[17] Liang, H., N. Saraf, Q. Hu, and Y. Xue, "Assimilation of enterprise systems: the effect of institutional pressures and the mediating role of top management", MIS Quarterly, vol. 31(1), 2007, pp. 59-87. 
[18] Lyytinen, K., and G.M. Rose, "Information system development agility as organizational learning", European Journal of Information Systems, vol. 15(2), 2006, pp. 183199.

[19] Marx, A.: 'Towards more robust model specification in QCA: Results from a methodological experiment', American Sociological Association, Philadelphia, PA, 2006.

[20] McDonald, M.L., and J.D. Westphal, "Getting by with the advice of their friends: CEOs' advice networks and firms' strategic responses to poor performance", Administrative Science Quarterly, vol. 48(1), 2003, pp. 1-32.

[21] McDonald, M.L., P. Khanna, and J.D. Westphal, "Getting them to think outside the circle: Corporate governance, CEOs' external advice networks, and firm performance", Academy of Management Journal, vol. 51(3), 2008, pp. 453-475.

[22] Melville, N., K. Kraemer, and V. Gurbaxani, "Review: Information technology and organizational performance: An integrative model of IT business value", MIS Quarterly, vol. 28(2), 2004, pp. 283-322.

[23] Mignerat, M., and S. Rivard, "Positioning the institutional perspective in information systems research", Journal of Information Technology, vol. 24(4), 2009, pp. 369-391.

[24] Minbaeva, D., T. Pedersen, I. Bjorkman, C.F. Fey, and H.J. Park, "MNC knowledge transfer, subsidiary absorptive capacity, and HRM", Journal of International Business Studies, vol. 34, 2003, pp. 586-599.

[25] Mitchell, V.L., "Knowledge integration and infromation technology project performance", MIS Quarterly, vol. 30(4), 2006, pp. 919-939.

[26] Montazemi, A.R., J.J. Pittaway, and H. Qahri-Saremi, "Significance of IT Governance in Transformational Government". Proc. Transformational Government (tGOV), London, UK March 18 - 19 2010, 2010

[27] Montazemi, A.R., and J.J. Pittaway, "Getting them to think outside the circle: IT governance, CIOs' external advice networks, and firm performance". Proc.

Transformational Government (tGOV), London, UK May 8th -9th 2012, 2012

[28] Montazemi, A.R., J.J. Pittaway, H. Qahri-Saremi, and Y. Wei, "Factors of stickiness in transfers of know-how between MNC units", Journal of Strategic Information Systems, vol. 21(1), 2012, pp. 31-57.

[29] Nebus, J., "Building collegial information networks: A theory of advice network generation", Academy of Management Review, vol. 31(3), 2006, pp. 615-637.

[30] Nograšek, J., and M. Vintar, "E-government and organisational transformation of government: Black box revisited?", Government Information Quarterly, vol. 31(1), 2014, pp. 108-118.

[31] Preston, D.S., and E. Karahanna, "Antecedents of IS strategic alignment: a nomological network", Information Systems Research, vol. 20(2), 2009, pp. 159-179.
[32] Ragin, C.C., "Set relations in social research: Evaluating their consistency and coverage", Political Analysis, vol. 14(3), 2006, pp. 291-310.

[33] Ragin, C.C., K.A. Drass, and S. Davey: 'FuzzySet/Qualitative Comparative Analysis 2.0', Department of Sociology, University of Arizona, Tucson, Arizona, 2006.

[34] Ragin, C.C., and H.M. Giesel, User's guide to fuzzyset/qualitative comparative analysis, University of Arizona, 2008 .

[35] Ross, J.W., P. Weill, and D. Robertson, Enterprise Architecture as Strategy: Creating a Foundation for Business Execution, Harvard Business School Press, Boston, MA, 2006.

[36] Swanson, E.B., and N.C. Ramiller, "The organizing vision in information systems innovation", Organization Science, vol. 8(5), 1997, pp. 458-474.

[37] Swanson, E.B., and N.C. Ramiller, "Innovating mindfully with information technology", MIS Quarterly, vol. 28(4), 2004, pp. 553-583.

[38] Tallon, P.P., and K.L. Kraemer, "Fact or fiction? A sensemaking perspective on the reality behind executives' perceptions of IT business value", Journal of Management Information Systems, vol. 24(1), 2007, pp. 13-54.

[39] Tallon, P.P., "A service science perspective on strategic choice, IT, and performance in US banking", Journal of Management Information Systems, vol. 26(4), 2010, pp. 219252

[40] Teo, H.H., K.K. Wei, and I. Benbasat, "Predicting intention to adopt interorganizational linkages: An institutional perspective", MIS Quarterly, vol. 27(1), 2003, pp. 19-49.

[41] Teo, T.S.H., S.C. Srivastava, C. Ranganathan, and J.W.K. Loo, "A framework for stakeholder oriented mindfulness: case of RFID implementation at YCH Group, Singapore", European Journal of Information Systems, vol. 20(2), 2011, pp. 201-220.

[42] Tiwana, A., and B. Konsynski, "Complementarities between organizational IT architecture and governance structure", Information Systems Research, vol. 21(2), 2010, pp. 288-304.

[43] Westphal, J.D., "Collaboration in the boardroom: Behavioral and performance consequences of CEO-board social ties", Academy of Management Journal, vol. 42(1), 1999, pp. 7-24.

[44] Wilkin, C.L., and R.H. Chenhall, "A review of IT governance: A taxonomy to inform accounting information systems", Journal of Information Systems, vol. 24(2), 2010, pp. 107-146.

[45] Zaheer, A., B. McEvily, and V. Perrone, "Does trust matter? Exploring the effects of interorganizational and interpersonal trust on performance", Organization Science, vol. 9(2), 1998, pp. 141-159. 